\title{
Unilateral versus Bilateral Landing after Spike Jumps in Male and Female Volleyball: A Systematic Review
}

\author{
José Afonso $^{1}\left(\mathbb{D}\right.$, Rodrigo Ramirez-Campillo ${ }^{2,3}{ }^{\mathbb{D}}$, Ricardo Franco Lima ${ }^{4}$, , Lorenzo Laporta ${ }^{5,6}$, Ana Paulo ${ }^{7}$, \\ Henrique de Oliveira Castro ${ }^{8}$, Gustavo De Conti Teixeira Costa ${ }^{9}$, Antonio García-de-Alcaraz ${ }^{10,11}$ (D), \\ Rui Araújo ${ }^{12} \mathbb{D}$, Ana Filipa Silva ${ }^{13,14}$, Luca Paolo Ardigò $15,+(\mathbb{D}$ and Filipe Manuel Clemente $4,16, *,+\mathbb{D}$
}

\section{check for} updates

Citation: Afonso, J.; Ramirez-Campillo, R.; Lima, R.F.; Laporta, L.; Paulo, A.; Castro, H.d.O.; Costa, G.D.C.T.;

García-de-Alcaraz, A.; Araújo, R.; Silva, A.F.; et al. Unilateral versus Bilateral Landing after Spike Jumps in Male and Female Volleyball: A Systematic Review. Symmetry 2021, 13, 1505.

https://doi.org/10.3390/sym13081505

Academic Editors: Sergei D. Odintsov and Jan Awrejcewicz

Received: 15 May 2021

Accepted: 9 August 2021

Published: 17 August 2021

Publisher's Note: MDPI stays neutral with regard to jurisdictional claims in published maps and institutional affiliations.

Copyright: (c) 2021 by the authors. Licensee MDPI, Basel, Switzerland. This article is an open access article distributed under the terms and conditions of the Creative Commons Attribution (CC BY) license (https:/ / creativecommons.org/licenses/by/ $4.0 /)$.
1 Centre for Research, Education, Innovation, and Intervention in Sport, Faculty of Sport of the University of Porto, 4200-450 Porto, Portugal; jneves@fade.up.pt

2 Department of Physical Activity Sciences, Universidad de Los Lagos, 8320000 Santiago, Chile; r.ramirez@ulagos.cl

3 Centro de Investigación en Fisiología del Ejercicio, Facultad de Ciencias, Universidad Mayor, 7500000 Santiago, Chile

4 Escola Superior Desporto e Lazer, Instituto Politécnico de Viana do Castelo, Rua Escola Industrial e Comercial de Nun'Álvares, 4900-347 Viana do Castelo, Portugal; ricardo.lima@esdl.ipvc.pt

5 Campus Santiago, Universidade Regional Integrada do Alto Uruguai e das Missões, Santiago 97711-500, Brazil; Lorenzo.laporta@urisantiago.br

6 Escola de Educação Física e Fisioterapia, Universidade Federal do Rio Grande do Sul (UFRGS), Rua Felizardo, $\mathrm{n}^{\circ} 750$, Jardim Botânico, Porto Alegre 90690-200, Brazil

7 CIDEFES, Universidade Lusófona, Campo Grande 376, 1749-024 Lisbon, Portugal; p3707@ulusofona.pt

8 Physical Education Department, Universidade Federal de Mato Grosso, Cuiabá 78060-900, Brazil; henriquecastro@ufmt.br

9 Faculty of Physical Education and Dance, Federal University of Goiás, Goiânia 74968-755, Brazil; conti02@ufg.br

10 Department of Education, University of Almería, 04120 Almería, Spain; galcaraz@ual.es

11 SPORT Research Group (CTS-1024), CERNEP Research Center, University of Almeria, 04120 Almeria, Spain

12 Avenida Carlos de Oliveira Campos, University Institute of Maia-ISMAI, Castêlo da Maia, 4475-690 Maia, Portugal; D011754@ismai.pt

13 N2i, Polytechnic Institute of Maia, 4475-690 Maia, Portugal; d011824@ipmaia.pt

14 The Research Centre in Sports Sciences, Health Sciences and Human Development (CIDESD), 5001-801 Vila Real, Portugal

15 Department of Neurosciences, Biomedicine and Movement Sciences, School of Exercise and Sport Science, University of Verona, 37131 Verona, Italy; luca.ardigo@univr.it

16 Instituto de Telecomunicações, Departamento da Covilhã, 1049-001 Lisboa, Portugal

* Correspondence: filipeclemente@esdl.ipvc.pt

+ These authors share last authorship.

Abstract: Background: The spike is a key action in volleyball, and the landing technique and its asymmetries are commonly associated with an increased risk of injury. Objectives: The aim of this systematic review was to assess how male and female volleyball players land (i.e., unilaterally, or bilaterally) after spike jumps in matches and analytical settings (field or laboratory). Methods: The Preferred Reporting Items for Systematic Reviews and Meta-Analyses 2020 guidelines were followed, with eligibility criteria defined according to participants, interventions, comparators, study design (PICOS): (p) healthy indoor volleyball players of any sex, age group, or competitive level; (i) exposure to landing after spike actions during official matches AND/OR simulated 6 vs. 6 games AND/OR analytical training conditions AND/OR laboratorial experiments; (c) not mandatory; (o) data on landing mechanics after spike actions, including reporting of whether the landing was unilateral or bilateral; (s) no restrictions imposed on study design. Searches were performed in seven electronic databases (Cochrane Library, EBSCO, PubMed, Scielo, Scopus, SPORTDiscus, and Web of Science) on 23 April 2021. Results: Automated searches provided 420 results. Removal of 119 duplicates resulted in 301 records being screened for titles and abstracts. A total of 25 studies were eligible for full-text analysis. Of these, eight studies were deemed eligible for inclusion in the review. Studies showed that (i) attackers landed asymmetrically $68 \%$ of the times (61\% left leg, $7 \%$ right leg); (ii) bilateral asymmetries were observed for the hip, knee, and ankle joints; (iii) bilateral asymmetries were 
observed even when players were instructed to land evenly on two feet; (iv) landing contact of the leg opposite to the hitting arm preceded the contact of the homolateral leg. One match analysis study showed that men landed more often on the left (31.5\%) or right foot $(8.5 \%)$ than women $(23.7 \%$ and $1.6 \%$ ). Conclusions: Studies analyzing spike landing showed a prevalence of unilateral landings (mostly the left leg first, for right-handed players) in men and women but more prevalently in men. Registration INPLASY202140104, DOI: 10.37766/inplasy2021.4.0104.

Keywords: volleyball; asymmetric kinematics; biomechanics; injury risk; match analysis; strengthshortening cycle; symmetry

\section{Introduction}

Volleyball is a team sport played by six players on each side of the court, divided by a net; the ball cannot be grabbed, and each team is limited to three contacts with the ball in each turn (with few exceptions where four contacts are allowed). In this sport, there are more symmetrically biased actions (e.g., set, pass) and predominantly asymmetric actions (e.g., the serve, the spike). The game has different phases, termed game complexes [1,2], that present distinct game patterns and have their own functional specificities (for a modern overview and synthesis, see Figure 1 in Martins et al. [3]). A major feature of volleyball is the predominant role played by vertical jumps [4,5]. In this context, muscles can be used as force dissipators in jump landings [6], which are common in volleyball (e.g., after spiking, blocking, serving, and setting) $[4,7,8]$. Strategies associated with energy dissipation patterns are relevant for understanding performance and injury risk [6], and in volleyball, an improper landing might be associated with noncontact ACL injuries [9-12].

Volleyball players regularly land unilaterally after a spike action [13], due to a shift in the center of gravity arising from the asymmetric technique that is required by the spike jump [14]. The asymmetric biomechanics of the trunk and upper limb in volleyball increase the likelihood of the right-handed players landing on the left leg first [15]. Even when the landing seems symmetric, the left leg usually plays a more prominent role in absorbing the impact for right-handed players [16]. Therefore, spike jumps are more strongly associated with unilateral landing than other volleyball jumps [13]. Unilateral landing seems to be associated with an increased risk of ACL injury [17]. In professional women volleyball players, $61.7 \%$ of ACL injuries occurred after landing from a spike jump, and the left knee was the most injured (64.7\%) [12], suggesting the presence of asymmetry in how players land after spike jumps. Landing mechanics can be altered by surface and shoe type [18-20]. While the focus of our work relies on indoor volleyball, different surface features and shoe types may interact with landing dynamics and-perhaps-with the consequences of landing for the knee and other joints, but this issue is beyond the scope of our current work.

A study sampling two matches among four National Collegiate Athletic Association (NCAA) Division IA women volleyball teams revealed that players landed on the left foot after a spike jump in $35 \%$ of occasions, the right foot in $10 \%$ of actions, and symmetrically (on a rough visual inspection) in 55\% of occasions [11]. Another study assessed 12 volleyball matches from the Italian men's and women's A1 and A2 professional leagues [13], analyzing video footage to categorize the landing techniques into unilateral or bilateral. After a spike jump, men fell $31.5 \%$ of times with left foot first, $8.5 \%$ with the right foot first, and $60 \%$ of the time with both feet (again, through visual inspection of video footage). For women, the values were $23.7 \%, 1.6 \%$, and $74.7 \%$, respectively, with significant sex-based differences. This is at odds with the greater incidence of ACL injuries reported in female athletes $[10,21]$ since men were more asymmetric in landing after a spike jump and raises doubts on whether asymmetric landing is causally linked with noncontact ACL injuries in volleyball. Regardless of the exact relationships between unilateral landing mechanics, performance, and injury risk, it seems that women volleyball players are exposed differently than men to unilateral landing. 


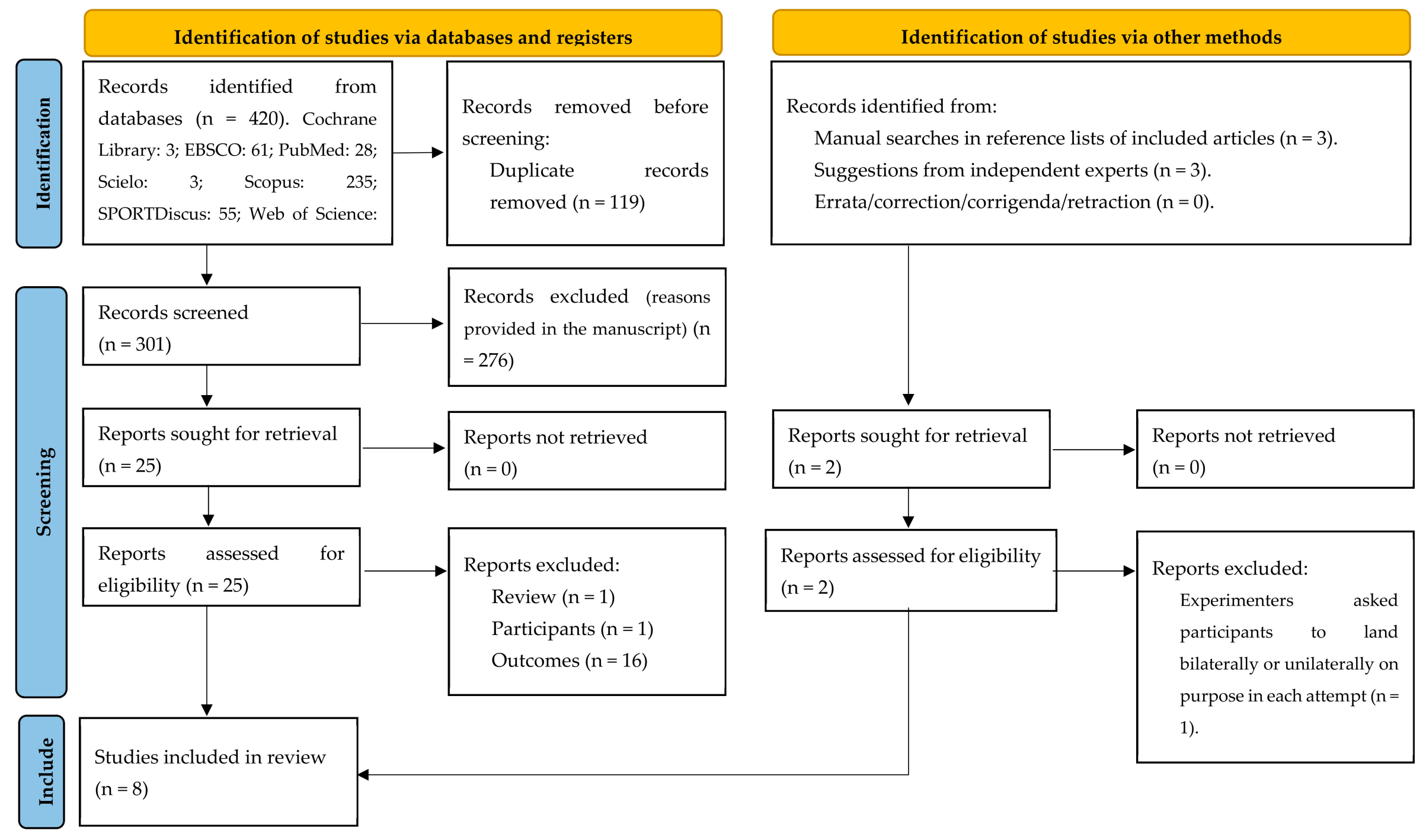

Figure 1. PRISMA 2020 flow diagram. 
The landing technique may also be influenced by the attack zone [13]: men more often landed on one foot when attacking from positions 4 and 6, and on two feet when attacking from positions 1, 2, and 3. For women, landing on one foot was predominant when attacking from position 6 , and landing on two feet was more common for all other positions [13]. Only in attacks from position 4 were the differences between men and women significant, leading to a more asymmetric landing in men [13]. In the same study, quicker attack tempos were associated more strongly with asymmetric landing [13]. These results suggest that, beyond the asymmetric constraints imposed by the spike action, the landing technique may depend on attack zone and tempo, and again denote subtle, but potentially relevant gender-based differences. This couples landing mechanics with task-related constraints and renders conscious control of landing a difficult undertaking, especially under time-constrained and real-match conditions.

In a laboratorial context, Xu, Jiang, Cen, Baker and Gu [14] collected vertical ground reaction forces upon landing after a spike action in 12 semi-professional male volleyball players. A tosser (i.e., thrower) sets the ball for the spiker, with no variability in ball trajectory constraints and no opposition. Landing on a single leg presented smaller knee flexion $\left(-74.3 \pm 15.2^{\circ}\right.$ vs. $\left.-99.8 \pm 17.6^{\circ}\right)$ and hip flexion $\left(-43.0 \pm 12.8^{\circ}\right.$ vs. $\left.-74.3 \pm 10.9^{\circ}\right)$ angles and greater ankle plantarflexion angle $\left(-19.9 \pm 8.8^{\circ}\right.$ vs. $\left.-8.6 \pm 8.3^{\circ}\right)$ than landing on both legs, as well as the greater knee $(-42.8 \pm 5.8$ vs. $-29.4 \pm 5.6 \mathrm{~W} / \mathrm{kg})$ and hip power $(-57.9 \pm 10.5$ vs. $-30.5 \pm 6.9 \mathrm{~W} / \mathrm{kg})$. The authors stated that players should consciously increase hip and knee flexion when landing with one foot to avoid ACL injuries [14]. However, this study had no data on ACL injury, and it is doubtful that players can consciously focus on their landing (i.e., using an internal attentional focus) in real-match scenarios (where they will be attending external cues, e.g., ball trajectory, blockers). Additionally, as the match progresses, fatigue sets in, altering both unilateral and bilateral landing kinematics [22].

Concerning the internal or external focus in the landing technique, one study assessed the effects of a single session of video and verbal feedback on the spike jump landing technique in 19 female volleyball players (age, 12-14 years) [9]. Four weeks after the single feedback session, the 10 players in the intervention group had increased maximal hip and trunk flexion in landing after a spike action, in comparison with the control group (no feedback), while differences in knee flexion and ankle dorsiflexion were nonsignificant. However, the control and experimental groups were recruited from different teams and schools; therefore, confounding effects may have occurred [23]. The conditions under which the athletes performed the spike, and the landing were highly standardized, reducing the external validity of the study. Another study with 14 male adult volleyball players [24] showed that a drop landing and landing from a spike jump had substantial differences in lower limb biomechanics, raising the issue of the validity of the laboratory test used to assess landing biomechanics. Considering the diversity of study designs and findings, systematizing the existing body of knowledge may provide relevant information and point to future directions for research and practice.

According to the relevance of the spike action in volleyball, as well as the different outcomes obtained from different training or competitive contexts, our main goal was to systematically review studies assessing how male and female volleyball players land (i.e., unilaterally, or bilaterally) after spike jumps in matches or analytical settings (field or laboratory), and to assess gender-based differences. The working hypothesis was that unilateral landings were more common than bilateral landings, especially in official matches and in men. Based on a preliminary overview of the literature, data are scarce to generate a hypothesis concerning injury risk.

\section{Materials and Methods}

This systematic review followed the Preferred Reporting Items for Systematic Reviews and Meta-Analyses (PRISMA) guidelines [25]. The review methods were established before initiating the research, and protocol registration preceded the search. 


\subsection{Eligibility Criteria}

Studies were eligible if providing original research within the scope of this review and published in peer-reviewed journals, without limitations concerning language or publication date. Excluded records included conference abstracts, books and book chapters, editorials, letters to the editor, trial registrations, all types of reviews, essays, or original research in nonpeer-reviewed journals. Following PRISMA guidelines, inclusion and exclusion criteria were defined according to participants, interventions, comparators, outcomes, and study design (PICOS) (see Table 1).

Table 1. Inclusion and exclusion criteria based on scope and PICOS.

\begin{tabular}{|c|c|c|}
\hline Rule & Inclusion Criteria & Exclusion Criteria \\
\hline Participants & $\begin{array}{l}\text { Indoor volleyball players of any sex, age } \\
\text { group, or competitive level. }\end{array}$ & $\begin{array}{l}\text { Players of sports other than indoor volleyball } \\
\text { (i.e., sitting volleyball, beach volleyball). } \\
\text { Unhealthy or injured indoor } \\
\text { volleyball players. } \\
\text { Physical education students. }\end{array}$ \\
\hline Interventions & $\begin{array}{l}\text { Exposure to landing after spike actions } \\
\text { during official matches and/or simulated } \\
6 \text { vs. } 6 \text { games and/or analytical training } \\
\text { conditions and/or laboratorial experiments. }\end{array}$ & $\begin{array}{l}\text { No exposure to landing after spike actions. } \\
\text { Spiking actions performed starting from a box } \\
\text { or following incomplete executions (i.e., only } \\
\text { a part of the full action). } \\
\text { Landing after jumps other than spike actions } \\
\text { (e.g., block, jump serve). } \\
\text { Landing conditioned by the researchers } \\
\text { (e.g., mandatory to land with only one foot on } \\
\text { the force platform). }\end{array}$ \\
\hline Comparators & Not mandatory. & $\begin{array}{l}\text { No study was excluded on the basis } \\
\text { of comparators. }\end{array}$ \\
\hline Outcomes & $\begin{array}{l}\text { Data on landing biomechanics after spike } \\
\text { actions, including reporting of whether the } \\
\text { landing was unilateral or bilateral. } \\
\text { If available, data were collected on the } \\
\text { degree of asymmetry in joints degree of } \\
\text { flexion, and reaction forces. }\end{array}$ & $\begin{array}{l}\text { Absence of data characterizing landing after } \\
\text { spike actions as being unilateral or bilateral. } \\
\text { Data on bilateral differences was } \\
\text { compromised by the authors (e.g., excluding } \\
\text { asymmetric landings from the analysis). }\end{array}$ \\
\hline Study design & No restrictions imposed on study design. & $\begin{array}{c}\text { No study was excluded on the basis of } \\
\text { study design. }\end{array}$ \\
\hline
\end{tabular}

\subsection{Information Sources}

Searches were performed in seven electronic databases (Cochrane Library, EBSCO, PubMed, Scielo, Scopus, SPORTDiscus, and Web of Science) on 23 April 2021, after protocol registration. Following the selection of articles to be included, a manual search was conducted in their reference lists to retrieve additional studies that fit our eligibility criteria. Then, the list of included articles and the inclusion criteria were sent to two independent experts to help identify additional relevant articles. We established two criteria that experts had to fulfill, namely, (i) hold a PhD in sports sciences; (ii) have peer-reviewed publications in volleyball in journals with impact factor according to the Journal Citation Reports ${ }^{\circledR}$. The experts were not provided with our search strategy, to avoid biasing their own searches. Upon completion of all these steps, on 1 May 2021, the databases were again consulted in search of errata or retractions of any included study [23].

\subsection{Search Strategy}

Code lines used in Cochrane Library, PubMed, Scopus, SPORTDiscus and Web of Science: ["volleyball" (title/abstract)] AND ["spik" OR "attack*" OR "smash" OR "hit" OR "hitting" (all fields)] AND ["land" (all fields)]. Code lines used in Scielo and EBSCO: ["volleyball" (all fields)] AND ["spik*" OR "attack" OR "smash"” OR "hit" OR "hitting" 
(all fields)] AND [“land*” (all fields)]. Search results were exported to EndNote 20.0.1 for Mac (Clarivate Analytics). No filters or limits were applied.

\subsection{Selection Process}

J.A. and F.M.C. performed searches, removed duplicates, screened titles and abstracts, and analyzed full texts independently. No disagreements were found at this stage. The process was repeated for searches within reference lists and suggestions provided by the external experts.

\subsection{Data Collection Process}

Relevant data items were defined a priori, to avoid biasing the analyses [26]. L.L. and R.F.L. completed initial data extraction independently. In case of discrepancies, J.A., R.A., and A.P. discussed the situation until consensus was achieved. Data were recorded in Excel spreadsheets created specifically for this review.

\subsection{Data Items}

Outcomes consisted of data relative to how players landed after spike actions. These data include, if available, (i) the number of jumping actions; (ii) number and characteristics of unipodal versus bipodal landings; (iii) attack zone; (iv) attack tempo; (v) straight run-up versus feints; (vi) action immediately preceding the attack action (e.g., defense, block, serve reception, waiting); (vii) positional status (i.e., wing-spiker, opposite, middle-blocker, setter).

Additional information concerning study characteristics was extracted as follows: (i) sample size and features (e.g., age group, sex, level of the competition, number of players or teams; if available, number of right- and left-handed players); (ii) intra- and/or inter-observer reliability of the observations; (iii) study design; (iv) funding sources and potential conflicts of interest.

\subsection{Study Risk of Bias Assessment}

Upon inspection of the literature, the authors felt that no scale for assessment of methodological quality and risk of bias was appropriate for the review purposes, especially considering the possibility that many retrieved studies would use an observational design. For observational studies, the reported intra- and interobserver reliability were assessed. For nonrandomized studies, ROBINS-I was planned [27], and RoB 2 for randomized studies [28]. J.A. and F.M.C. independently assessed the risk of bias. There were no disagreements to report.

\subsection{Effect Measures}

The main outcomes of interest were unipodal and bipodal landing biomechanics.

\subsection{Synthesis Methods}

No meta-analysis was planned. A narrative synthesis of the results was provided.

\subsection{Reporting Risk of Bias Assessment}

Since no meta-analysis was planned, reporting risk of bias assessment could not be performed.

\subsection{Certainty Assessment}

The authors considered that no existing scale for assessing methodological quality was appropriate for observational studies addressing the research question. Therefore, for observational studies, The Strengthening the Reporting of Observational Studies in Epidemiology (STROBE) checklist was provided [29], while the certainty of the evidence was assessed subjectively. A.G.-d.-A., G.d.C.T.C., and H.d.O.C. independently assessed observational studies. For multiarm studies, certainty was assessed using the Grading of 
Recommendations Assessment, Development, and Evaluation (GRADE) [30-32]. J.A. and F.M.C. assessed multiarm studies. In case of disagreements, A.P., R.F.L., and J.A. intervened to provide a final decision.

\section{Results}

\subsection{Study Selection}

Automated searches provided 420 results (Cochrane Library: 3; EBSCO: 61; PubMed: 28; Scielo: 3; Scopus: 235; SPORTDiscus: 55; Web of Science: 35). Removal of 119 duplicates resulted in 301 records being screened for titles and abstracts. At this stage, 276 studies were excluded (85 were not original research; 191 failed to comply with one or more PICOS criteria). In total, 25 studies were eligible for full-text analysis, of which 16 were excluded due to not meeting participants [24] or outcome-related criteria [33-47]. Even when assessing landing after a spike jump (which not every study performed), usually only one lower limb was assessed, which detracted from assessing bilateral differences in landing mechanics. For example, in the study of Bisseling, Hof, Bredeweg, Zwerver, and Mulder [33], only one lower limb could contact the force platform upon landing, while in the study of Cronin, Bressel, and Finn [34], all jumps with asymmetric landing were excluded from the analysis. A study was excluded because it was a review, despite the abstract suggesting it was original research [48]. Finally, the study of Xu, Jiang, Cen, Baker, and $\mathrm{Gu}$ [14] (cited in the introduction) was excluded because athletes performed landings on a single leg in one experimental condition, and on both legs in another condition (i.e., not an unconstrained spiking action).

The reference lists of the seven studies that were deemed eligible were searched for retrieving relevant studies that had not emerged in the automated searches. Three potentially relevant titles were retrieved, of which two were excluded upon inspection of the abstracts. One study required full-text analysis but was excluded because the players had to land bilaterally or unilaterally on request [49]. Two independent experts suggested three additional studies, of which two had not emerged during our initial searches: one study only assessed the upper limbs, but the other study fulfilled eligibility criteria and was added to the review [50]. Errata, corrigenda/correction, and retractions were searched for the included studies, to ensure that the most correct versions of the data were considered [23], but none was found. In sum, eight studies had data on unilateral and bilateral landing and were deemed eligible for analysis [9,11,13,16,50-53]. The process is summarized in the PRISMA 2020 flow diagram [25] (Figure 1).

\subsection{Study Characteristics}

Study characteristics are detailed in Table 2. Five studies used laboratorial/field analytical approaches to assess landing from spike jumps under controlled conditions, of which four used an observational design $[16,50,51,53]$, and one adopted a randomized design to assess the effects of a single session of augmented feedback in landing from a spike jump [9]. Three studies used match analysis to assess landings in official matches [11,13,52]. Samples ranged from 4 players [52] to 92 players [13]. Four studies assessed male players [16,51-53], three assessed female players $[9,11,50]$, and one assessed both [13]. The fact that only one study assessed both men and women strongly constraints gender-based comparisons. One study assessed adolescents [9], while all others assessed adult players [11,13,16,50-53], with competition level in adults ranging from university-level players [16] to elite players of the World Championships [52]. In five studies, all players were right-handed [9,13,16,51,52], one study had 16 right-handed and 2 left-handed players [53], and two studies did not report on handedness [11,50]. Two studies analyzed outside hitters [16,52], two analyzed all attackers [11,13], and four studies did not report on the positional role $[9,50,51,53]$. Only one study attempted to correlate spike jumps with attack zone and tempo [13]. 
Table 2. Study characteristics and main results.

Study and Purpose

Adams, Kiefer, Panchuk, Hunter, MacPherson, and Spratford [51] Funding sources and competing interests: Unreported.

Bermejo, Palao, and Valadés [50]
Funding sources and competing interests: Unreported.

Experimental study with four conditions: hop jump (single leg), drop landing, spike jump, and augmented reality (augmented reality - smart glasses displayed a visual animation of a virtual nonplayer character setting) spike were carried out during the testing session).

Twelve male right-handed volleyball players volunteered (age: $18.8 \pm 3.2$ years; height: $1.87 \pm 0.8 \mathrm{~m}$; body mass:

$81.2 \pm 8.9 \mathrm{~kg}) ; 6$ from the Centre of Excellence program at the Australian Institute of Sport, 6 from an Australian Volleyball League. Positional role of the players was not detailed.

Observational study of the spike jump (Camcorder used to record the movement and Known3D software to analyze the spike jump). All subjects executed 5 consecutive spike jumps in practice context.

10 female volleyball players from Spanish Super League (age: $23.7 \pm 5.7$ years; height: $1.82 \pm 0.1 \mathrm{~m}$; body mass:

$73.6 \pm 5.0 \mathrm{~kg})$. All subjects had played in international competitions.

Handedness and positional role of the players was not detailed.

Match analysis of official matches.

6 women's and 6 men's professional volleyball matches of the

Lobietti, Coleman, Pizzichillo, and Merni [13] Funding sources and competing interests: Unreported. respectively, were right-handers; data restricted to 1st Italian league. 48 men and 48 women (of whom 45 and 47 right-handed players). Age, height, and body mass: unreported by the authors.

All types of attacker were considered.
Bilateral differences on landing from a spike jump: $68 \%$ of participants landed asymmetrically, with $61 \%$ making initial contact on the left leg and $7 \%$ on the left foot.

Bilateral differences on landing from a spike jump for ankle flexion and knee flexion. Leg of dominant hand: ankle flexion $139.2 \pm 11.1^{\circ}$; knee flexion $159.2 \pm 7.4^{\circ}$. Leg of nondominant hand: ankle flexion $130.4 \pm 9.8^{\circ}$; knee flexion $153.1 \pm 10.5^{\circ}$.

Unclear if the bilateral differences achieved statistical significance.

Men landed more often on the left (31.5\%) or right foot $(8.5 \%)$ than women $(23.7 \%$ and $1.6 \%)$. Men landed more often unilaterally than bilaterally after attacking in zones $4(70.1 \%)$ and $6(78.6 \%)$, but not in zones $2(15.8 \%), 1(17.6 \%)$ and $3(24.2 \%)$. Women landed more with one foot when attacking in zone $6(61.8 \%)$, less when attacking in zones $1(35.7 \%)$ $4(31.3 \%), 3(17.1 \%)$, and $2(13.3 \%)$.

Men landed unilaterally in $78.7 \%$ of quick attacks in zone 4 , and in $53.6 \%$ of slow attacks. Women landed unilaterally in $44.5 \%$ of quick attacks in zone 4 , and in $21.0 \%$ of slow attacks. 
Table 2. Cont.

Angle at the instant of the initial contact with the floor-right versus left foot: $29.5 \pm 3.1^{\circ}$ vs. $32.7 \pm 3.6^{\circ}$; right versus left

ankle: $124.4 \pm 15.7$ vs. $124.4 \pm 12.4^{\circ}$; right versus left knee:

$161.7 \pm 6.0^{\circ}$ vs. $160.0 \pm 7.5^{\circ}$; right versus left hip:

$149.1 \pm 26.2^{\circ}$ vs. $150.2 \pm 19.8^{\circ}$.

Range of motion-right versus left foot:

$16.5 \pm 4.7^{\circ}$ vs. $25.3 \pm 4.7^{\circ}$; right versus left ankle:

$30.2 \pm 13.9^{\circ}$ vs. $36.7 \pm 16.6^{\circ}$; right versus left knee:

$17.9 \pm 4.2^{\circ}$ vs. $22.2 \pm 5.0^{\circ}$; right versus left hip: $7.9 \pm 7.2^{\circ}$ vs. $11.0 \pm 11.0^{\circ}$

Maximal flexion velocity-right versus left foot:

$886.6 \pm 66.1^{\circ}$ / s vs. $981.9 \pm 105.7^{\circ}$ / s; right versus left ankle: $1396.3 \pm 107.2^{\circ} / \mathrm{s}$ vs. $1408.6 \pm 64.1^{\circ} / \mathrm{s}$; right versus left knee:

$798.3 \pm 98.4^{\circ}$ /s vs. $852.1 \pm 94.9^{\circ} / \mathrm{s}$; right versus left hip:

$517.5 \pm 111.7^{\circ} / \mathrm{s}$ vs. $603.7 \pm 109.6^{\circ} / \mathrm{s}$. Long landing

Marquez, Masumura, and Ae [16] Funding sources and competing interests: Unreported.
"Simulated Court": landing tasks on force platform. Normal and long jumping were assessed.

Six male, university, right-handed, outside hitters (age: $19.6 \pm 0.7$ years; height: $1.86 \pm 0.0 \mathrm{~m}$; body mass: $78.3 \pm 5.5 \mathrm{~kg})$.

Angle at the instant of the initial contact with the floor-right

versus left foot: $26.3 \pm 6.6^{\circ}$ vs. $24.7 \pm 2.8^{\circ}$; right versus left ankle: $119.7 \pm 20.9$ vs. $125.8 \pm 12.2^{\circ}$; right versus left knee: $158.6 \pm 9.8^{\circ}$ vs. $160.0 \pm 6.8^{\circ}$; right versus left hip:

$$
131.6 \pm 22.2^{\circ} \text { vs. } 125.8 \pm 13.8^{\circ}
$$

Range of motion-right versus left foot:

$15.3 \pm 10.2^{\circ}$ vs. $17.1 \pm 4.5^{\circ}$; right versus left ankle:

$19.9 \pm 13.7^{\circ}$ vs. $23.2 \pm 12.7^{\circ}$; right versus left knee:

$18.2 \pm 7.1^{\circ}$ vs. $16.0 \pm 4.1^{\circ}$; right versus left hip:

$11.8 \pm 21.6^{\circ}$ vs. $7.3 \pm 11.1^{\circ}$

Maximal flexion velocity-right versus left foot: $797.2 \pm 223.4^{\circ} / \mathrm{s}$ vs. $785.9 \pm 179.7^{\circ} / \mathrm{s}$; right versus left ankle: $1323.6 \pm 265.5^{\circ} / \mathrm{s}$ vs. $1142.5 \pm 259.9^{\circ} / \mathrm{s}$; right versus left knee: $973.5 \pm 139.6^{\circ} / \mathrm{s}$ vs. $1041.6 \pm 122.2^{\circ} / \mathrm{s}$; right versus left hip: $715.0 \pm 99.5^{\circ} / \mathrm{s}$ vs. $754.1 \pm 89.9^{\circ} / \mathrm{s}$

For all cases, unclear if bilateral differences were statistically significant. 
Table 2. Cont.

\section{Study and Purpose}

Marquez, Masumura, and Ae [52] Funding sources and competing interests: Unreported.

Parsons and Alexander [9] Funding sources: Manitoba Health Research Council Studentship.

Competing interests: Unreported.

\section{Study Design and Sample}

Videotaped with two high-speed VTR cameras during the Men's World Championship of 2006.

4 male right-handed outside hitters (age: $24.8 \pm 3.4$ years; height: $1.98 \pm 0.1 \mathrm{~m}$; body mass: $91.0 \pm 7.0 \mathrm{~kg}$ ).

Kinematic measurements on spike jump task. A repeated measures design was used (4 week time frame). Five successfull spikes were performed.

Sixteen healthy female right-handed volleyball players from 2 middle schools (age: $13.2 \pm 0.4$ years in intervention group and $13.1 \pm 0.3$ in controls; height and body mass: unreported by the authors).

Positional roles of the players unreported by the authors. interests: Unreported.

Pavlov and Buzhinskiy [53] Funding sources and competing Laboratorial-based spike task.

Eighteen male volleyball players from a University team (age:

$19.9 \pm 0.9$ years, height: $1.91 \pm 0.2 \mathrm{~m}$, body mass

$89.3 \pm 1.4 \mathrm{~kg}$ ), of which 16 were right-handed and 2 left-handed.

\section{Main Outcomes}

Eleven of the twelve landings (91.6\%) were left-footed first, with the right leg elevated at floor contact.

Both groups showed bilateral asymmetries in landing for hip and knee flexion, and ankle dorsiflexion (i.e., all the assessed

variables). Intervention group-right versus left ankle

dorsiflexion: $17.3 \pm 6.9^{\circ}$ vs. $15.3 \pm 9.3^{\circ}$; right versus left knee

flexion: $85.3 \pm 23.2^{\circ}$ vs. $86.4 \pm 24.3^{\circ}$; right versus left hip

flexion: $69.6 \pm 30.1^{\circ}$ vs. $59.4 \pm 18.8^{\circ}$. Unclear whether these differences reached statistical significance.
Indoor condition

Contact of the opposite leg on landing, in comparison with the homonymous leg: delay of $2 \pm 0.6 \mathrm{~ms}$.

Positional role of the players was not detailed.

Recordings of two matches among four National Collegiate

Athletic Association Division IA female volleyball teams.
Number of players assessed and handedness: unreported by

Tillman, Hass, Brunt, and Bennett [11] Funding sources and competing interests: Unreported. the authors.

Age, height, and body mass: unreported by the authors.
Bilateral landing $=55 \%$; right-foot landing $=10 \%$; left-foot landing $=35 \%$.

All types of attacker were considered. 


\subsection{Risk of Bias in Studies}

Only one study was randomized (cluster-randomized) [9]. Accordingly, RoB 2 (extension for cluster randomization) was used to assess the risk of bias. There were some concerns in risk of bias arising from randomization, due to insufficient information concerning how randomization was achieved and assessment of baseline differences, and no information concerning allocation sequence concealment. Low risk was identified in bias arising from the timing of identification or recruitment of participants. Some concerns were identified in risk of bias due to deviations from the intended intervention, as participants and people delivering the intervention were aware of the intervention. There was a highrisk bias due to missing outcome data: the two groups were small (10 in the intervention group and 9 in the control group), and three participants quit (1 in the intervention group, 2 in the control group). Since two were from the smaller group, this created an imbalance between intervention and controls, and there was no attempt to demonstrate that the result was not biased by missing data. There was a high risk of bias in the measurement of the outcome: assessors were not blinded, and the assessments had some subjectivity, confirmed by reported intraclass correlation coefficients $<0.75$. Additionally, there was a high risk of bias in the selection of the reported results, since there was no pre-registered protocol, certain outcomes were excluded after being collected due to poor reliability (e.g., knee valgus angle), and the choice of average values was carried out a posteriori (again, due to problems with the reliability of measurements). This study was assessed with an overall high risk of bias.

For the remaining seven studies, which were observational, information was extracted concerning if and how they performed intra- and/or interobserver reliability. Four studies $(57.1 \%)$ conducted laboratorial/field analytical experiments [16,50,51,53]. None of these studies reported intra- or interobserver reliability, not even indirectly (e.g., reporting reliability values of previous studies). For the automated devices and processes, no reference values were provided (e.g., typical error, standard error of measurement), except in one study (14.3\%), which reported a $0.5 \mathrm{~mm}$ calibration error [50]. No study had blinded assessors. Three studies $(42.9 \%)$ performed match analysis [11,13,52]. Two of them $(28.6 \%)$ did not report intra- or interobserver reliability of the observations, and one study (14.3\%) [52] reported the maximum relative error of the automated analysis through direct linear transformation ( $1.7 \%$ for width, $0.4 \%$ for length, and $4.2 \%$ for height). However, in this study [52], only three actions were selected for each subject; two researchers performed this selection, but there was no reporting of interobserver reliability for the choices that were made.

\subsection{Results of Individual Studies}

The results of individual studies are also compiled in Table 2 (see above). Laboratorial studies showed that (i) attackers landed $68 \%$ of the times asymmetrically ( $61 \%$ of times on the left leg, $7 \%$ on the right leg) [51]; (ii) bilateral asymmetries were present (unclear if statistically significant) in ankle flexion and knee flexion [50], as well as in foot and hip angles, and range of motion and maximal flexion velocity of the foot, ankle, knee and hip [16]; (iii) bilateral asymmetries in hip and knee flexion in both experimental and control groups (unclear whether statistical significance was reached), despite instructions to land evenly on two feet [9]; (iv) landing contact of the leg opposite to the hitting arm preceded the contact of the homolateral leg (no mention if statistically significant) [53]. Since the laboratorial studies only included men or women (but not both) and had very different study designs, gender-based comparisons could not be established.

A match analysis study with men showed that $91.6 \%$ of the landings after a spike jump occurred with the left foot first [52], and another showed that women landed $35 \%$ of times on the left foot, $10 \%$ on the right foot, and $55 \%$ bilaterally [11]. The authors stated that the majority of unilateral landings occurred in zone 4 but provided no data, and the player role was unreported [11]. 
Another match analysis study showed that men landed more often on the left (31.5\%) or right foot (8.5\%) than women (23.7\% and $1.6 \%)$ [13]. Other findings of this study [13] are as follows: (i) men landed more often unilaterally than bilaterally after attacking in zones $4(70.1 \%)$ and $6(78.6 \%)$ but not in zones $2(15.8 \%), 1(17.6 \%)$, and $3(24.2 \%)$; (ii) women landed predominantly with one foot when attacking in zone $6(61.8 \%)$, less prominently when attacking in zones $1(35.7 \%)$ and $4(31.3 \%)$, and even less in zones $3(17.1 \%)$ and $2(13.3 \%)$. The authors explored the interaction between attack tempo and attack zone [13] and found that (i) men landed unilaterally in $78.7 \%$ of quick attacks in zone 4 , and in $53.6 \%$ of slow attacks, suggesting that quicker attack tempos increase the rate of unilateral landing; (ii) women landed unilaterally in $44.5 \%$ of quick attacks in zone 4 , and in $21.0 \%$ of slow attacks. This was the only study affording comparisons between men and women, showing that there are gender-based differences in exposure to unilateral landing.

\subsection{Certainty of Evidence}

Since only one multiarm study was found [9], GRADE was not applied. As a result of having a single study and its high risk of bias, the certainty of the evidence was deemed very low. For the observational studies $[11,13,14,16,51-53]$, the STROBE checklist was applied (Table 3). Most studies did not explicitly address funding sources and competing interests, and $71.4 \%$ of studies did not address potential sources of bias or explain how the study size was arrived at. Across the board, characteristics of the participants were highly incompletely reported, and studies did not address whether there was missing data. There was no reporting of intra- or interobserver reliability in these studies and, where applicable, no reporting of standard errors of measurement or similar data. The certainty of evidence arising from these observational studies was very low. 
Table 3. Checklist of items that should be included in reports of observational studies (STROBE).

\begin{tabular}{|c|c|c|c|}
\hline & Item No & Recommendation & Percentage of Studies Reporting \\
\hline \multirow{2}{*}{ Title and abstract } & \multirow{2}{*}{1} & (a) Indicate the study's design with a commonly used term in the title or the abstract. & $100 \%(7 / 7)$ \\
\hline & & (b) Provide in the abstract an informative and balanced summary of what was performed and what was found. & $100 \%(7 / 7)$ \\
\hline \multicolumn{4}{|l|}{ Introduction } \\
\hline Background/rationale & 2 & Explain the scientific background and rationale for the investigation being reported. & $100 \%(7 / 7)$ \\
\hline Objectives & 3 & State-specific objectives, including any prespecified hypotheses. & $100 \%(7 / 7)$ \\
\hline \multicolumn{4}{|l|}{ Methods } \\
\hline Study design & 4 & Present key elements of study design early in the paper. & $57.1 \%(4 / 7)$ \\
\hline Participants & 6 & Give the eligibility criteria and the sources and methods of selection of participants. & $100 \%(7 / 7)$ \\
\hline Variables & 7 & Clearly define all outcomes, exposures, predictors, potential confounders, and effect modifiers. Give diagnostic criteria, if applicable. & $100 \%(7 / 7)$ \\
\hline Data sources/measurement & 8 & $\begin{array}{c}\text { For each variable of interest, give sources of data and details of methods of assessment (measurement). Describe comparability of } \\
\text { assessment methods if there is more than one group. }\end{array}$ & $100 \%(7 / 7)$ \\
\hline Bias & 9 & Describe any efforts to address potential sources of bias. & $28.6 \%(2 / 7)$ \\
\hline Study size & 10 & Explain how the study size was arrived at. & $28.6 \%(2 / 7)$ \\
\hline Quantitative variables & 11 & Explain how quantitative variables were handled in the analyses. If applicable, describe which groupings were chosen and why. & $100 \%(7 / 7)$ \\
\hline \multirow{3}{*}{ Statistical methods } & \multirow{3}{*}{12} & (a) Describe all statistical methods. & $100 \%(7 / 7)$ \\
\hline & & (c) Explain how missing data were addressed. & $0 \%(0 / 7)$ \\
\hline & & (d) If applicable, describe analytical methods taking account of sampling strategy. & $57.1 \%(4 / 7)$ \\
\hline \multicolumn{4}{|l|}{ Results } \\
\hline \multirow{3}{*}{ Participants } & \multirow{3}{*}{13} & $\begin{array}{l}\text { (a) Report numbers of individuals at each stage of study-e.g., numbers potentially eligible, examined for eligibility, confirmed eligible, } \\
\text { included in the study, completing follow-up, and analysed. }\end{array}$ & $42.9 \%(3 / 7)$ \\
\hline & & (b) Give reasons for nonparticipation at each stage. & $0 \%(0 / 7)$ \\
\hline & & (c) Consider use of a flow diagram. & $0 \%(0 / 7)$ \\
\hline \multirow{2}{*}{ Descriptive data } & \multirow{2}{*}{14} & (a) Give characteristics of study participants (e.g., demographic, clinical, social) and information on exposures and potential confounders. & $0 \%(0 / 7)$ \\
\hline & & (b) Indicate number of participants with missing data for each variable of interest. & $28.6 \%(2 / 7)$ \\
\hline Outcome data & 15 & Report numbers of outcome events or summary measures over time. & $100 \%(7 / 7)$ \\
\hline \multirow{2}{*}{ Main results } & \multirow{2}{*}{16} & $\begin{array}{l}\text { (a) Give unadjusted estimates and, if applicable, confounder-adjusted estimates and their precision (e.g., 95\% confidence interval). Make } \\
\text { clear which confounders were adjusted for and why they were included. }\end{array}$ & $14.3 \%(1 / 7)$ \\
\hline & & (b) Report category boundaries when continuous variables were categorized. & $14.3 \%(1 / 7)$ \\
\hline Other analyses & 17 & Report other analyses conducted-e.g., analyses of subgroups and interactions, and sensitivity analyses. & $57.1 \%(4 / 7)$ \\
\hline
\end{tabular}


Table 3. Cont.

\begin{tabular}{|c|c|c|c|}
\hline & Item No & Recommendation & Percentage of Studies Reporting \\
\hline \multicolumn{4}{|l|}{ Discussion } \\
\hline Key results & 18 & Summarise key results with reference to study objectives. & $100 \%(7 / 7)$ \\
\hline Limitations & 19 & $\begin{array}{l}\text { Discuss limitations of the study, considering sources of potential bias or imprecision. Discuss both direction and magnitude of any } \\
\text { potential bias. }\end{array}$ & $14.3 \%(1 / 7)$ \\
\hline Interpretation & 20 & $\begin{array}{l}\text { Give a cautious overall interpretation of results considering objectives, limitations, multiplicity of analyses, results from similar studies, and } \\
\text { other relevant evidence. }\end{array}$ & $71.4 \%(5 / 7)$ \\
\hline Generalisability & 21 & Discuss the generalisability (external validity) of the study results. & $85.7 \%(6 / 7)$ \\
\hline \multicolumn{4}{|l|}{ Other information } \\
\hline
\end{tabular}




\section{Discussion}

\subsection{Summary of Evidence}

We reviewed the evidence concerning how volleyball players land after a spike jump, focusing on bilateral differences since the spike action in volleyball is highly asymmetric [54]. Eight studies were included in our review. Evidence from match analysis and laboratorial studies $[9,11,13,16,51-53]$ suggests that landing after a spike jump is asymmetric in two forms: (i) landings where one foot contacts the ground first (usually, the left foot for right-handed players) and (ii) landings where the two feet contact the ground simultaneously, but one foot absorbs a greater percentage of the impact than the other (again, the left foot for right-handed players). Men landed unilaterally more often than women, and there were hints that attack zone and tempo may be associated with the rate of unilateral landings, but only one study provided solid data for that [13]. Further genderbased differences could not be assessed based on existing studies, given that (i) most only included men or women but not both, and (ii) they had very different study designs.

Micro-asymmetries exist, with unilateral landing being common [16]. These detailed analyses are unlikely to be feasible through match analysis studies unless the technology is developed, and pressure sensors can be incorporated in the tennis shoes of the athletes (this was not attempted in the analyzed studies). Although field-based tests with force platforms could probably help in this regard, the study design would likely demand tasks with highly reduced external validity, i.e., tasks that are extremely simplified in comparison with full, unrestrained gameplay. Even under laboratorial conditions and guaranteeing that male volleyball players landed on both feet into a force platform, Marquez, Masumura, and Ae [16] discovered that landing was asymmetric, with the left leg absorbing a greater percentage of the impact. Players also landed with one foot in front of the other, perhaps explaining at least part of this asymmetry, as each foot will have a different relationship with the inertial center of mass during landing [16]. Confidence in evidence is currently very low and there is no information establishing a relationship between asymmetrical/symmetrical landing from spike jumps and performance or injury risk.

It has been proposed that coaches teach different landings strategies or techniques to volleyball players $[12,14]$, but it is doubtful that players will be able to consciously monitor how they land during real-game actions. Instead, Lobietti, Coleman, Pizzichillo, and Merni [13] suggest that, due to the predominance of single-leg landings in quicker attacks, especially on the left side of the court, coaches should start warming up on the right side of the court and using slower attack tempos so that players start by using techniques that will more likely result in landing with both feet simultaneously. As the authors state, this is at odds with what usually occurs, especially during the warm-up for official matches [13]. It is worth noting that the warm-up for official matches does not require the traditional spike warm-up, as teams can request a separate warm-up period and engage with alternative activities. This is seldom used due to tradition, not due to any inherent limitations of the rules.

Encouraging athletes to land with both feet to prevent knee injury [52,55] is aligned with ideas of reducing muscle imbalances [55]. However, asymmetry is an integral part of the volleyball spike, strengthening the hypothesis that asymmetry can be functional. Athletes adapt to the asymmetric requirements of spiking, including asymmetric landing, extending the physical and biological basis of asymmetry to a sports setting [56]. Asymmetries have shown benefits in running during states of fatigue [57]. Bilateral asymmetries of up to $15-20 \%$ are considered normal and are prevalent in sports, but there is likely an upper limit or threshold where asymmetries may become pathologic [58]. Furthermore, asymmetries (and their magnitude) are modulated by the type of test being used for assessment, chronological age, maturity, sex, type of sport, period of the season, modulators that may preclude the establishment of a particular threshold for increased injury risk [59].

Noncontact ACL injuries are the most prevalent noncontact injuries in volleyball, in both sexes, usually following a sudden deceleration while cutting or pivoting and landing from a jump $[60,61]$. Although our study lacks data to afford direct comparisons, it 
seems that those injuries are more related to other landing characteristics than kinematic or kinetic bilateral asymmetries. Landing with reduced knee and hip flexion and increased knee valgus may increase the ACL's injury risk $[9,62,63]$. Moreover, the higher incidence of injury in women suggests they occur due to a greater knee joint valgus showed by women than men [64-67], which may result from neuromuscular and/or structural differences (e.g., augmented joint laxity in women and different pelvic anatomy [68]. Therefore, coaches should take care of limiting the knee dynamic valgus during a single-leg landing, becoming less taxing to the ACL and maybe reducing ACL noncontact injuries [64].

Disappointing results were found in the quality of the studies gathered in this review, and confidence in evidence was very low. More match analysis studies are required to assess the percentage of unilateral landings and whether they associate with attack zone and tempo, or other relevant variables. Analytical studies should provide two force platforms and avoid excluding asymmetric landings by design. If possible, these studies should create more realistic attacking conditions, with varied attack directions and levels of opposition. Experimental studies on whether these landing patterns can be modified should use randomized designs and assess if such modifications impair attack efficacy. Match analysis studies should provide inter- and/or intrarater reliability [1], while analytical studies should guarantee the blinding of the assessors [23]. Funding sources and competing interests should be openly acknowledged; if no funding and competing interests exist, authors should explicitly state that.

\subsection{Limitations}

The reduced number of studies available $(n=8)$, the heterogeneity in designs (match analysis, laboratorial spike landing tasks) and populations (i.e., from young players beginning to engage with the 6 vs. 6 games to top-level adult players), high risk of bias, lack of reporting of reliability measures, and/or standard errors of measurement and the overall very low confidence in cumulative evidence requires further studies to be performed to provide a clearer understanding of how volleyball players land after a spike jump. Furthermore, existing studies did not provide data concerning performance or injury risk, and therefore, the relationships between asymmetrical landings, performance, and injuries are currently unknown. Additionally, we did not analyze surface or shoe type, which could have implications for landing mechanics and its consequences for the joints.

\subsection{Practical Implications and Suggestions for Future Studies}

The practical implications of our findings are quite straightforward and include the following:

(i) Unilateral landings are very common after a spike jump. This seems to be universal, i.e., regardless of playing level or sex (although it seems more prevalent in men). Therefore, coaches should acknowledge this reality and, instead of asking players to land on two feet, they should design conditioning programs improving unilateral landing, developing both the strength levels and the coordination required to properly cushion the asymmetric landings.

(ii) Since the studies suggest that quicker attack tempos associate with an increased percentage of unilateral landing, players with hip, knee, or ankle pain or with previous injuries in these joints could benefit from practicing with slower attack tempos, at least temporarily, until symptoms resolve.

(iii) Men seem to be more exposed to unilateral landing than women. If this is confirmed by further studies, perhaps conditioning programs for men should incorporate a greater percentage of single-leg strength training, with an emphasis on the eccentric component.

For future studies, we suggest the following:

(i) Match analysis studies should use video cameras with high resolution and high sampling rates, as well as provide measures of interobserver reliability of the observations. 
These studies should also provide context for the landing types (e.g., attack zone and tempo).

(ii) Laboratorial or field studies should consider all landings and not just symmetric landings, to provide a more complete understanding of how players behave when landing after a spike jump. These studies should implement parallel randomized or cross-over randomized designs where task constraints (e.g., provenience of the ball, attack zone and tempo, type of opposition) are purposefully manipulated to better understand their effects on landing mechanics. These experiments could also test whether different shoe types and distinct indoor surfaces interfere with landing mechanics.

(iii) Long-term injury-related implications of bilateral and unilateral landings on different surfaces could be assessed using cluster-randomized designs, as each team usually practices on the same surface during the week.

(iv) The effects of fatigue on landing mechanics after a spike jump should also be assessed and, if a relationship is established, this may provide important information for coaches to manage the training sessions.

(v) More studies are required comparing men and women under similar conditions, to better understand gender-based differences in terms of exposure to unilateral landing and the mechanical implications for each gender.

\section{Conclusions}

Studies analyzing spike landing showed a prevalence of unilateral landings (mostly the left leg first, for right-handed players) in men and women, with a suggestion that men may be more exposed than women. This asymmetry seems to be inherent to the spike action and may be unavoidable, despite proposals of strategies for circumventing it. Knee injuries are more prevalent in women, but the only study comparing men and women established that unilateral landing was more prevalent in men $(40.0 \%)$ than in women $(25.3 \%)$, raising doubts concerning the theoretical association between unilateral landing and knee injuries. It is also unclear how these landing asymmetries relate to neuromuscular or structural differences, such as an increased joint laxity in females and differences in pelvic structure and lower extremity alignment.

\section{Other Information}

Protocol and Registration

The protocol was published in INPLASY202140104, DOI: 10.37766/inplasy2021.4.0104. Initial searches in Scielo and in Cochrane Library retrieved zero results; therefore, we changed the protocol and eliminated the third code line ("land") specifically for these two databases.

Author Contributions: Conceptualization: J.A. and F.M.C.; methodology (general): J.A., R.R.-C., L.P.A. and F.M.C.; selection process: J.A., A.F.S. and F.M.C.; data collection and initial coding: J.A., R.F.L., L.L. and L.P.A.; data analysis: J.A., R.R.-C., L.P.A. and F.M.C.; assessments of risk of bias and certainty of evidence: J.A., A.P., H.d.O.C., G.D.C.T.C., A.G.-d.-A., R.A. and F.M.C.; writingoriginal draft: J.A., R.R.-C. and F.M.C.; writing-review and editing: J.A., R.R.-C., R.F.L., L.L., A.P., H.d.O.C., G.D.C.T.C., A.G.-d.-A., R.A., A.F.S., L.P.A. and F.M.C.; supervision: J.A., L.P.A. and F.M.C. Contributors not fulfilling all these criteria were not included in the authors' list and instead were named in the acknowledgments. All authors have read and agreed to the published version of the manuscript.

Funding: This research received no external funding.

Institutional Review Board Statement: Not applicable to systematic reviews.

Informed Consent Statement: Not applicable to systematic reviews.

Data Availability Statement: The relevant data are provided in the tables of the manuscript. 
Acknowledgments: We thank Carmen Fernandez Echeverría and Patrícia Coutinho for providing expert input in suggesting potentially relevant studies to be included in the final sample, after having analyzed the list of studies we had selected, as well as the inclusion and exclusion criteria. Filipe Manuel Clemente: This work is supported by Fundação para a Ciência e Tecnologia/Ministério da Ciência, Tecnologia e Ensino Superior through national funds and, when applicable, co-funded EU funds under the project UIDB/50008/2020 but without directly funding this research.

Conflicts of Interest: The authors declare no conflict of interest.

\section{References}

1. Laporta, L.; Afonso, J.; Mesquita, I. Interaction network analysis of the six game complexes in high-level volleyball through the use of Eigenvector Centrality. PLoS ONE 2018, 13, e0203348. [CrossRef] [PubMed]

2. Laporta, L.; Medeiros, A.I.A.; Vargas, N.; Castro, H.O.; Bessa, C.; João, P.V.; Costa, G.C.T.; Afonso, J. Coexistence of Distinct Performance Models in High-Level Women's Volleyball. J. Hum. Kinet. 2021, 78, 161-173. [CrossRef]

3. Martins, J.B.; Mesquita, I.; Mendes, A.; Santos, L.; Afonso, J. Inter-team variability in high-level women's volleyball from the perspective of Social Network Analysis: An analysis in critical game scenarios. Int. J. Perform. Anal. Sport 2021, 21, 564-578. [CrossRef]

4. Nikolaidis, P.T.; Afonso, J.; Clemente-Suarez, V.J.; Alvarado, J.R.; Driss, T.; Knechtle, B.; Torres-Luque, G. Vertical Jumping Tests versus Wingate Anaerobic Test in Female Volleyball Players: The Role of Age. Sports 2016, 4, 9. [CrossRef]

5. Nikolaidis, P.T.; Gkoudas, K.; Afonso, J.; Clemente-Suarez, V.J.; Knechtle, B.; Kasabalis, S.; Kasabalis, A.; Douda, H.; Tokmakidis, S.; Torres-Luque, G. Who jumps the highest? Anthropometric and physiological correlations of vertical jump in youth elite female volleyball players. J. Sports Med. Phys. Fit. 2017, 57, 802-810. [CrossRef]

6. Minetti, A.E.; Ardigò, L.P.; Susta, D.; Cotelli, F. Using leg muscles as shock absorbers: Theoretical predictions and experimental results of drop landing performance. Ergonomics 1998, 41, 1771-1791. [CrossRef]

7. Lima, R.F.; Palao, J.M.; Clemente, F.M. Jump Performance During Official Matches in Elite Volleyball Players: A Pilot Study. J. Hum. Kinet. 2019, 67, 259-269. [CrossRef] [PubMed]

8. Afonso, J.; Mesquita, I.; Marcelino, R.; Silva, J.A. Analysis of the setter's tactical action in high-performance women's volleyball. Kinesiology 2010, 42, 82-89.

9. Parsons, J.L.; Alexander, M.J. Modifying spike jump landing biomechanics in female adolescent volleyball athletes using video and verbal feedback. J. Strength Cond. Res. 2012, 26, 1076-1084. [CrossRef]

10. Salci, Y.; Kentel, B.B.; Heycan, C.; Akin, S.; Korkusuz, F. Comparison of landing maneuvers between male and female college volleyball players. Clin. Biomech. 2004, 19, 622-628. [CrossRef]

11. Tillman, M.D.; Hass, C.J.; Brunt, D.; Bennett, G.R. Jumping and Landing Techniques in Elite Women's Volleyball. J. Sports Sci. Med. 2004, 3, 30-36.

12. Devetag, F.; Mazzilli, M.; Benis, R.; La Torre, A.; Bonato, M. Anterior cruciate ligament injury profile in Italian Serie A1-A2 women's volleyball league. J. Sports Med. Phys. Fit. 2018, 58, 92-97. [CrossRef]

13. Lobietti, R.; Coleman, S.; Pizzichillo, E.; Merni, F. Landing techniques in volleyball. J. Sports Sci. 2010, 28, 1469-1476. [CrossRef]

14. Xu, D.; Jiang, X.; Cen, X.; Baker, J.S.; Gu, Y. Single-Leg Landings Following a Volleyball Spike May Increase the Risk of Anterior Cruciate Ligament Injury More Than Landing on Both-Legs. Appl. Sci. 2021, 11, 130. [CrossRef]

15. Wagner, H.; Tilp, M.; von Duvillard, S.P.; Mueller, E. Kinematic analysis of volleyball spike jump. Int. J. Sports Med. 2009, 30, 760-765. [CrossRef]

16. Marquez, W.Q.; Masumura, M.; Ae, M. The effects of jumping distance on the landing mechanics after a volleyball spike. Sports Biomech. 2009, 8, 154-166. [CrossRef]

17. Morgan, K.D.; Donnelly, C.J.; Reinbolt, J.A. Elevated gastrocnemius forces compensate for decreased hamstrings forces during the weight-acceptance phase of single-leg jump landing: Implications for anterior cruciate ligament injury risk. J. Biomech. 2014, 47, 3295-3302. [CrossRef]

18. Dragoo, J.L.; Braun, H.J. The Effect of Playing Surface on Injury Rate. Sports Med. 2010, 40, 981-990. [CrossRef]

19. Dragoo, J.L.; Braun, H.J.; Harris, A.H. The effect of playing surface on the incidence of ACL injuries in National Collegiate Athletic Association American Football. Knee 2013, 20, 191-195. [CrossRef] [PubMed]

20. Melissa, M.M.; Ronald, B.B. Effects of Playing Surface and Shoe Type on ACL Tears in Soccer Players. Am. J. Eng. Appl. Sci. 2016, 9, 1150-1157. [CrossRef]

21. Renstrom, P.; Ljungqvist, A.; Arendt, E.; Beynnon, B.; Fukubayashi, T.; Garrett, W.; Georgoulis, T.; Hewett, T.E.; Johnson, R.; Krosshaug, T.; et al. Non-contact ACL injuries in female athletes: An International Olympic Committee current concepts statement. Br. J. Sports Med. 2008, 42, 394-412. [CrossRef]

22. Borotikar, B.S.; Newcomer, R.; Koppes, R.; McLean, S.G. Combined effects of fatigue and decision making on female lower limb landing postures: Central and peripheral contributions to ACL injury risk. Clin. Biomech. 2008, 23, 81-92. [CrossRef] [PubMed]

23. Higgins, J.P.; Thomas, J.; Chandler, J.; Cumpston, M.; Li, T.; Page, M.J.; Welch, V. Cochrane Handbook for Systematic Reviews of Interventions, 2nd ed.; John Wiley \& Sons: Chichester, UK, 2019.

24. Edwards, S.; Steele, J.R.; McGhee, D.E. Does a drop landing represent a whole skill landing and is this moderated by fatigue? Scand. J. Med. Sci. Sports 2010, 20, 516-523. [CrossRef] 
25. Page, M.J.; McKenzie, J.E.; Bossuyt, P.M.; Boutron, I.; Hoffmann, T.C.; Mulrow, C.D.; Shamseer, L.; Tetzlaff, J.M.; Akl, E.A.; Brennan, S.E.; et al. The PRISMA 2020 statement: An updated guideline for reporting systematic reviews. BMJ 2021, $372, \mathrm{n} 71$. [CrossRef]

26. Spieth, P.M.; Kubasch, A.S.; Penzlin, A.I.; Illigens, B.M.-W.; Barlinn, K.; Siepmann, T. Randomized controlled trials-A matter of design. Neuropsychiatr. Dis. Treat. 2016, 12, 1341-1349. [CrossRef] [PubMed]

27. Sterne, J.A.; Hernán, M.A.; Reeves, B.C.; Savović, J.; Berkman, N.D.; Viswanathan, M.; Henry, D.; Altman, D.G.; Ansari, M.T.; Boutron, I.; et al. ROBINS-I: A tool for assessing risk of bias in non-randomised studies of interventions. BMJ 2016, 355 , i4919. [CrossRef]

28. Sterne, J.A.; Savović, J.; Page, M.J.; Elbers, R.G.; Blencowe, N.S.; Boutron, I.; Cates, C.J.; Cheng, H.-Y.; Corbett, M.S.; Eldridge, S.M.; et al. RoB 2: A revised tool for assessing risk of bias in randomised trials. BMJ 2019, 366, 14898. [CrossRef] [PubMed]

29. von Elm, E.; Altman, D.G.; Egger, M.; Pocock, S.J.; Gøtzsche, P.C.; Vandenbroucke, J.P. The Strengthening the Reporting of Observational Studies in Epidemiology (STROBE) statement: Guidelines for reporting observational studies. Ann. Intern. Med. 2007, 147, 573-577. [CrossRef]

30. Guyatt, G.H.; Oxman, A.D.; Akl, E.A.; Kunz, R.; Vist, G.; Brozek, J.; Norris, S.; Falck-Ytter, Y.; Glasziou, P.; DeBeer, H.; et al. GRADE guidelines: 1. Introduction-GRADE evidence profiles and summary of findings tables. J. Clin. Epidemiol. 2011, 64, 383-394. [CrossRef] [PubMed]

31. Schünemann, H.J.; Mustafa, R.A.; Brozek, J.; Steingart, K.R.; Leeflang, M.; Murad, M.H.; Bossuyt, P.; Glasziou, P.; Jaeschke, R.; Lange, S.; et al. GRADE guidelines: 21 part 1 . Study design, risk of bias, and indirectness in rating the certainty across a body of evidence for test accuracy. J. Clin. Epidemiol. 2020, 122, 129-141. [CrossRef]

32. Schünemann, H.J.; Mustafa, R.A.; Brozek, J.; Steingart, K.R.; Leeflang, M.; Murad, M.H.; Bossuyt, P.; Glasziou, P.; Jaeschke, R.; Lange, S.; et al. GRADE guidelines: 21 part 2. Test accuracy: Inconsistency, imprecision, publication bias, and other domains for rating the certainty of evidence and presenting it in evidence profiles and summary of findings tables. J. Clin. Epidemiol. 2020, 122, 142-152. [CrossRef]

33. Bisseling, R.W.; Hof, A.L.; Bredeweg, S.W.; Zwerver, J.; Mulder, T. Are the take-off and landing phase dynamics of the volleyball spike jump related to patellar tendinopathy? Br. J. Sports Med. 2008, 42, 483-489. [CrossRef] [PubMed]

34. Cronin, J.B.; Bressel, E.; Finn, L. Augmented Feedback Reduces Ground Reaction Forces in the Landing Phase of the Volleyball Spike Jump. J. Sport Rehabil. 2008, 17, 148-159. [CrossRef] [PubMed]

35. García Lasluisa, E.D.; Vela Rodríguez, J.M.; Gibert, O.; Farril, A.R. Diferencias biomecánicas del remate de voleibol en jugadoras prejuveniles y juveniles. Rev. Cubana Invest. Bioméd. 2019, 38, 170-181.

36. Garrido-Castro, J.L.; Gil-Cabezas, J.; da Silva-Grigoletto, M.E.; Mialdea-Baena, A.; González-Navas, C. Tridimensional kinematic characterization of female volleyball spike. Rev. Andal. Med. Deport. 2017, 10, 69-73. [CrossRef]

37. Hrženjak, M.; Trajković, N.; Krističević, T. Effects of plyometric training on selected kinematic parameters in female volleyball players. Sport Sci. 2016, 9, 7-12.

38. Hussain, I.; Mohammad, A.; Khan, A. A relationship between anthropometrical and kinematical variables of spike jump of intercollegiate level male volleyball players. Int. J. Perform. Anal. Sport 2011, 11, 583-588. [CrossRef]

39. Kabaciński, J.; Dworak, L.B.; Murawa, M.; Rzepnicka, A. Dynamic load indicators for take-off-landing sequence in blocks and attacks of elite female volleyball players. Acta Bioeng. Biomech. 2016, 18, 41-46. [CrossRef]

40. Kabaciński, J.; Murawa, M.; Dworak, L.B.; MCzyŃSki, J. Differences in ground reaction forces during landing between volleyball spikes. Trends Sport Sci. 2017, 24, 87-92.

41. Kulig, K.; Joiner, D.G.; Chang, Y.J. Landing limb posture in volleyball athletes with patellar tendinopathy: A pilot study. Int. J. Sports Med. 2015, 36, 400-406. [CrossRef]

42. Richards, D.P.; Ajemian, S.V.; Wiley, J.P.; Brunet, J.A.; Zernicke, R.F. Relation between ankle joint dynamics and patellar tendinopathy in elite volleyball players. Clin. J. Sport Med. 2002, 12, 266-272. [CrossRef]

43. Richards, D.P.; Ajemian, S.V.; Wiley, J.P.; Zernicke, R.F. Knee joint dynamics predict patellar tendinitis in elite volleyball players. Am. J. Sports Med. 1996, 24, 676-683. [CrossRef]

44. Tai, W.H.; Peng, H.T.; Song, C.Y.; Lin, J.Z.; Yu, H.B.; Wang, L.I. Dynamic characteristics of approach spike jump tasks in male volleyball players. Appl. Sci. 2021, 11, 2710. [CrossRef]

45. Tsai, Y.J.; Chia, C.C.; Lee, P.Y.; Lin, L.C.; Kuo, Y.L. Landing kinematics, sports performance, and isokinetic strength in adolescent male volleyball athletes: Influence of core training. J. Sport Rehabil. 2021, 29, 65-72. [CrossRef]

46. West, T.; Ng, L.; Campbell, A. The effect of ankle bracing on knee kinetics and kinematics during volleyball-specific tasks. Scand. J. Med. Sci. Sports 2014, 24, 958-963. [CrossRef] [PubMed]

47. Allyn, D.A.; Stoner, L.J. The kinetics and kinematics of landing from two quick attack techniques. Int. J. Volleyb. Res. 2000, 2, 4-11.

48. Nemec, P.; Milošević, M.; Nemec, V.; Milošević, M. Production and development of muscle force in elite male volleyball players' spike. Sport Sci. 2016, 9, 32-40.

49. Tillman, M.D.; Criss, R.M.; Brunt, D.; Hass, C.J. Landing Constraints Influence Ground Reaction Forces and Lower Extremity EMG in Female Volleyball Players. J. Appl. Biomech. 2004, 20, 38. [CrossRef]

50. Bermejo, J.; Palao, J.M.; Valadés, D. Análisis del remate de voleibol en jugadoras de élite. Agon Int. J. Sport Sci. $2013,3,22-32$.

51. Adams, K.; Kiefer, A.; Panchuk, D.; Hunter, A.; MacPherson, R.; Spratford, W. From the field of play to the laboratory: Recreating the demands of competition with augmented reality simulated sport. J. Sports Sci. 2020, 38, 486-493. [CrossRef] [PubMed] 
52. Marquez, W.Q.; Masumura, M.; Ae, M. Spike-landing Motion of Elite Male Volleyball Players during Official Games. Int. J. Sport Health Sci. 2011, 9, 82-90. [CrossRef]

53. Pavlov, P.; Buzhinskiy, A. Comparison of spike techniques in college beach and classical volleyball. J. Phys. Educ. Sport 2019, 19, 742-747. [CrossRef]

54. Kim, D.-K.; Park, G.; Kuo, L.-T.; Park, W.-H. Isokinetic Performance of Shoulder External and Internal Rotators of Professional Volleyball Athletes by Different Positions. Sci. Rep. 2020, 10, 8706. [CrossRef]

55. Kumar, A. Electromyographical Bilateral Asymmetry of the lower limbs in Volleyball Players. Int. J. Sci. Res. $2014,3,245-247$.

56. Afonso, J.; Bessa, C.; Pinto, F.; Ribeiro, D.; Moura, B.; Rocha, T.; Vinícius, M.; Canário-Lemos, R.; Peixoto, R.; Clemente, F.M. Asymmetries in Athletic Performance. In Asymmetry as a Foundational and Functional Requirement in Human Movement: From Daily Activities to Sports Performance; Afonso, J., Bessa, C., Pinto, F., Ribeiro, D., Moura, B., Rocha, T., Vinícius, M., Canário-Lemos, R., Peixoto, R., Clemente, F.M., Eds.; Springer Science and Business Media LLC: Singapore, 2020; pp. 21-25.

57. Radzak, K.N.; Putnam, A.M.; Tamura, K.; Hetzler, R.K.; Stickley, C.D. Asymmetry between lower limbs during rested and fatigued state running gait in healthy individuals. Gait Posture 2017, 51, 268-274. [CrossRef]

58. Afonso, J.; Bessa, C.; Pinto, F.; Ribeiro, D.; Moura, B.; Rocha, T.; Vinícius, M.; Canário-Lemos, R.; Peixoto, R.; Clemente, F.M. Injury Prevention: From Symmetry to Asymmetry, to Critical Thresholds. In Asymmetry as a Foundational and Functional Requirement in Human Movement: From Daily Activities to Sports Performance; Afonso, J., Bessa, C., Pinto, F., Ribeiro, D., Moura, B., Rocha, T., Vinícius, M., Canário-Lemos, R., Peixoto, R., Clemente, F.M., Eds.; Springer Science and Business Media LLC: Singapore, 2020; pp. 27-31.

59. Bishop, C.; Read, P.; Chavda, S.; Jarvis, P.; Brazier, J.; Bromley, T.; Turner, A. Magnitude or Direction? Seasonal Variation of Interlimb Asymmetry in Elite Academy Soccer Players. J. Strength Cond. Res. 2020. [CrossRef]

60. Ireland, M.L. Anterior cruciate ligament injury in female athletes: Epidemiology. J. Athl. Train. 1999, 34, 150-154. [PubMed]

61. Griffin, L.Y.; Agel, J.; Albohm, M.J.; Arendt, E.A.; Dick, R.W.; Garrett, W.E.; Garrick, J.G.; Hewett, T.E.; Huston, L.; Ireland, M.L.; et al. Noncontact anterior cruciate ligament injuries: Risk factors and prevention strategies. J. Am. Acad. Orthop. Surg. 2000, 8, 141-150. [CrossRef] [PubMed]

62. Ireland, M.L. The female ACL: Why is it more prone to injury? Orthop. Clin. North. Am. 2002, 33, 637-651. [CrossRef]

63. Markolf, K.L.; Burchfield, D.M.; Shapiro, M.M.; Shepard, M.F.; Finerman, G.A.; Slauterbeck, J.L. Combined knee loading states that generate high anterior cruciate ligament forces. J. Orthop. Res. 1995, 13, 930-935. [CrossRef] [PubMed]

64. Russell, K.A.; Palmieri, R.M.; Zinder, S.M.; Ingersoll, C.D. Sex differences in valgus knee angle during a single-leg drop jump. J. Athl. Train. 2006, 41, 166-171. [PubMed]

65. Hewett, T.E.; Myer, G.D.; Ford, K.R.; Heidt, R.S.J.; Colosimo, A.J.; McLean, S.G.; van den Bogert, A.J.; Paterno, M.V.; Succop, P. Biomechanical measures of neuromuscular control and valgus loading of the knee predict anterior cruciate ligament injury risk in female athletes: A prospective study. Am. J. Sports Med. 2005, 33, 492-501. [CrossRef] [PubMed]

66. Ford, K.R.; Myer, G.D.; Toms, H.E.; Hewett, T.E. Gender differences in the kinematics of unanticipated cutting in young athletes. Med. Sci. Sports Exerc. 2005, 37, 124-129. [CrossRef]

67. Ford, K.R.; Myer, G.D.; Hewett, T.E. Valgus Knee Motion during Landing in High School Female and Male Basketball Players. Med. Sci. Sports Exerc. 2003, 35, 1745-1750. [CrossRef] [PubMed]

68. White, K.K.; Lee, S.S.; Cutuk, A.; Hargens, A.R.; Pedowitz, R.A. EMG power spectra of intercollegiate athletes and anterior cruciate ligament injury risk in females. Med. Sci. Sports Exerc. 2003, 35, 371-376. [CrossRef] 